\title{
Invited review: The application of alkaline phosphatase assays for the validation of milk product pasteurization
}

\author{
S. A. Rankin,,${ }^{\star 1}$ A. Christiansen, $\dagger$ W. Lee, $\ddagger$ D. S. Banavara,§ and A. Lopez-Hernandez* \\ *Department of Food Science, University of Wisconsin-Madison, Madison 53706 \\ †Nestle USA, Solon, OH 60143 \\ ‡Department of Animal Bioscience (Institute of Agricultural and Life Science), Gyeongsang National University, Jinju 660-701, South Korea \\ §Mead Johnson Nutrition, Evansville, IN 47721
}

\begin{abstract}
Standard practices for indirectly assessing the pasteurization status of milk products are primarily based on the thermal inactivation kinetics of the endogenous milk enzyme, alkaline phosphatase (ALP). This assessment provides an invaluable, if not required, tool for both regulatory and in-house process control and validation. Endogenous milk ALP manifests a slightly higher heat resistance than the pathogenic microflora upon which pasteurization time and temperature requirements are based. Hence, ALP activity is recognized and accepted as the method of choice for the rapid validation of milk product pasteurization. However, ALP assays have notable limitations that must be understood if they are to be administered and interpreted correctly and the results are to be applied judiciously. Issues such as the reactivation of heat-denatured ALP and the presence of both heat-stable and -labile microbial ALP are addressed. A discussion of ALP in the milk of nonbovine species is presented based on the limited literature available. Some discussion of research involving alternative pasteurization indicators also is presented. This article is intended to summarize the pertinent details of the ALP assay for dairy products (noting the basis and limitations of various methods) and the processing, handling, and known compositional factors that influence the assay results.
\end{abstract}

Key words: pasteurization, alkaline phosphatase assay, validation, review

\section{INTRODUCTION}

As with most perishable, potentially hazardous foods, the vast majority of milk products are subjected to a definitive thermal treatment (i.e., pasteurization).

Received May 4, 2010

Accepted September 3, 2010.

${ }^{1}$ Corresponding author: sarankin@wisc.edu
Given the complexities of modern milk processing equipment, global distribution systems, and increasing regulatory and industry demands, the alkaline phosphatase (ALP) test has been adopted by many countries as the standard assay for rapid validation of the milk pasteurization process. The premise of the ALP test is based on the thermal inactivation characteristics of the ALP enzyme endogenous to milk. In short, ALP is slightly more resistant to thermal inactivation than target bacterial pathogens (namely Coxiella burnetii and Mycobacterium tuberculosis, the most heat-resistant bacteria present in milk) are; thus, if ALP activities are greatly reduced, one can infer that the target bacterial pathogen population was at least similarly reduced and the legal thermal requirements for pasteurization were met. The detection of elevated ALP activity levels is primarily interpreted as an indication that either the milk was not sufficiently pasteurized or was contaminated with raw milk postpasteurization (Harding, 1991). Other interpretations of elevated ALP activities in finished products include the presence of bacterial ALP or the biochemical reactivation of the ALP enzyme. Contamination of pasteurized product with raw product has historically occurred as the result of pasteurization equipment failure, operator error, or mismanagement of raw and finished product disposition.

Although the ALP assay is widely used and recognized as the most appropriate method for verifying milk pasteurization, some studies have raised concerns over the ability of this test to validate pasteurization under certain circumstances. The prudent application of ALP-based assays must be based on an understanding of the assay and its limitations. Several different standard protocols exist for conducting ALP assays, each based on different sample preparatory methods or ALP substrate. Few comprehensive reviews can be found that detail currently used assay technologies. To that end, this paper will review the relevant details of the ALP assay for milk product pasteurization process verification. 


\section{ALKALINE PHOSPHATASE}

Alkaline phosphatase is a protein that was first described by Suzuki et al. (1907). It is abundantly present in nature and found in many human body tissues, such as liver, kidney, bone, and blood cells. It is found in milk (Shakeel-Ur-Rehman et al., 2003) and other bodily fluids from many organisms at varying levels. Alkaline phosphatase (EC 3.1.3.1) is a membranebound glycoprotein with sialic acid as sugar moiety. It is a phospho-monoesterase enzyme that catalyzes the hydrolysis of monoesters of phosphoric acid (at alkaline $\mathrm{pH})$, yielding phosphate and the corresponding alcohol. The abundance in nature and importance of this enzyme in biological systems has made ALP activity assessments one of the most commonly performed enzymatic tests (Miggiano et al., 1983).

Alkaline phosphatase is 1 of over 60 endogenous enzymes in raw bovine milk (Schlimme et al., 1997). The structure of ALP from Escherichia coli has been completely elucidated; however, mammalian ALP is known to have low AA sequence identity to ALP from E. coli (Bortolato et al., 2002). Purified bovine ALP was found to have a molecular mass of $187 \mathrm{kDa}$ and an isoelectric point ranging from $\mathrm{pH} 5.4$ to 6.0 (Vega-Warner et al., 1999). It has maximal activity in the $\mathrm{pH}$ range 9.65 to 10.1 at $37^{\circ} \mathrm{C}$. In its active form, the bovine ALP molecule forms complexes with zinc atoms that impart structural integrity and functional properties. The presence of metal ions is also believed to have a role in the ability of bovine ALP to regain enzymatic activity after thermal inactivation (Wright and Tramer, 1956). Bovine milk ALP is reported to be insoluble in fat and it is found in the lipid-water interface in milk. Alkaline phosphatase is associated with the milk fat globule membrane (MFGM) in raw milk (Kosikowski, 1988), which may be a consideration when concentrated or fractionated milk products, enriched in MFGM, are pasteurized. The breed of cow, volume of milk produced, and stage of lactation (Haab and Smith, 1956; Murthy et al., 1992) can influence the concentration of ALP in milk; however, earlier studies have demonstrated that the level of ALP in pooled milk is relatively constant (Burgwald, 1939). Given the challenges with ALP as a marker enzyme some studies have examined other possible enzymes such as adenosine deaminase (EC 3.5.4.4) (Martin et al., 1998; Schlimme et al., 1998) and $\gamma$-glutamyltransferase (EC 2.3.2.2) (dos Anjos et al., 1998).

The importance of bovine ALP to the dairy industry is related to its thermal inactivation properties. Because it is slightly more resistant to thermal treatment than the bacterial pathogens on which validated pasteurization processes are based, the thermal inactivation of milk ALP correlates well with thermally induced bacterial death (van Bever, 1943). Such correlations have established and strengthened the hypothesis that the ALP assay could be used as a criterion for pasteurization verification (Sanders and Sager, 1948). More recent work also has found similar correlations comparing the inactivation responses of Salmonella senftenberg and Listeria monocytogenes (Eckner, 1992). The thermal inactivation of ALP has been found to follow first-order kinetics, and the denaturation midpoint for milk ALP has been obtained at $56^{\circ} \mathrm{C}$ for a 30 -min heating (Levieux et al., 2007). Indigenous milk ALP also can be inactivated by high-pressure processing in the range 400 to $800 \mathrm{MPa}$ and at temperatures ranging from 5 and $40^{\circ} \mathrm{C}$ (Rademacher and Hinrichs, 2006). It has been reported that ALP inactivation induced by high-pressure homogenization is due to mechanical forces such as shear, cavitation, and impact (Picart et al., 2006). Pulsed electric field treatment can effect the inactivation of both the bovine and microbial ALP present in raw skim milk (Shamsi et al., 2008). Also, predictive equations based on the inactivation of ALP in a pilot-plant HTST pasteurizer have been developed to assess the effectiveness of commercial pasteurization processes (McKellar et al., 1994). Hence, assessment of ALP activity is used as a rapid, indirect indicator of pasteurization status in finished milk products.

\section{METHODS FOR ALP MEASUREMENT}

Assays employed to detect ALP activity can be broadly classified into 4 types: colorimetric, fluorometric, chemiluminescent, and immunochemical methods. These methods have been adopted for use over many years; however, only the colorimetric, fluorometric, and chemiluminescent types have been recognized as validated methods for pasteurization verification in the dairy industry. Such recognition or acceptance is based on assay performance scrutiny by various regulatory agencies, trade organizations, and academic institutions. Some concern exists about these different tests with regard to their status as validated ALP assays. For instance, the grade "A" Pasteurized Milk Ordinance (PMO; DHHS-FDA, 2007) states that an ALP assay must be done by an electronic procedure; the ordinance lists a fluorometric and chemiluminescent method, but then describes the colorimetric reaction and finally refers the reader to a text (Rocco, 2004) with numerous assays, both visual and electronic. The National Conference on Interstate Milk Shipments (NCIMS) recently (2009) adopted a proposal omitting reference to colorimetric assays and limiting approved methods to the fluorometric and chemiluminescent methods as is manifest in the 2009 PMO. The European Commission 


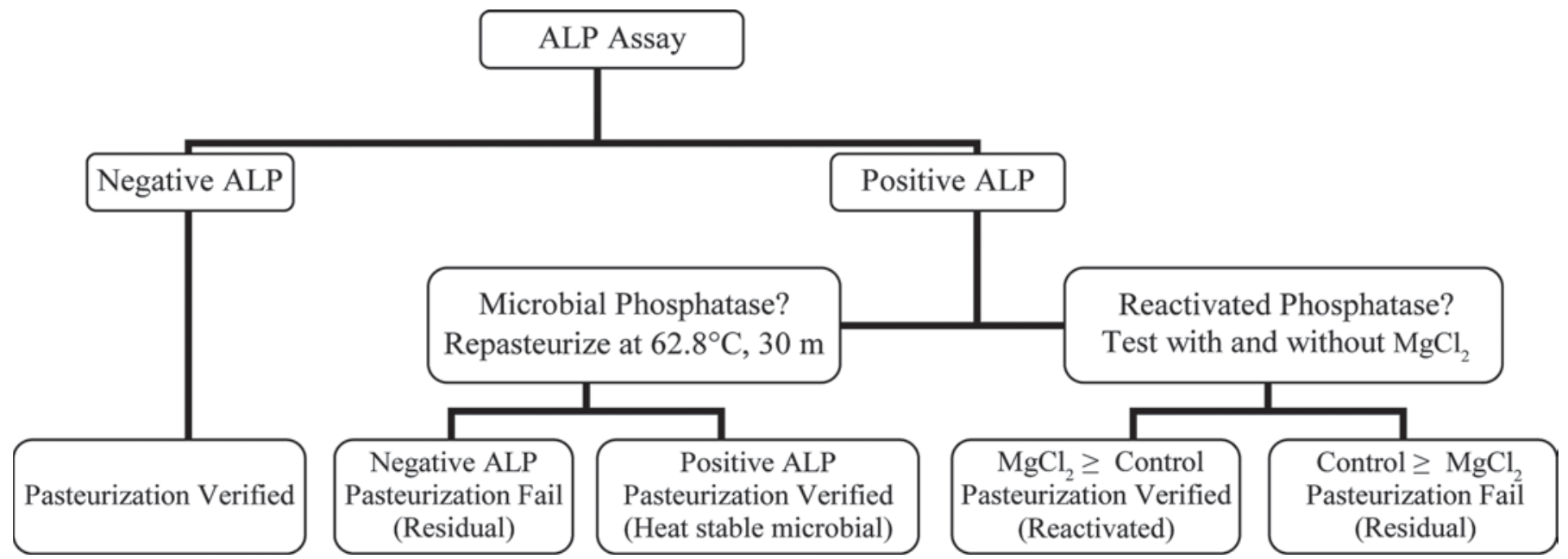

Figure 1. General logic to determine the pasteurization status of dairy products tested with the alkaline phosphate (ALP) assay.

standards (2007) reference a fluorometric method (International Organization for Standardization 11816-1) as the approved testing means, yet also denote conditions for alternative methods and the need for ongoing work in areas including nonbovine milk and nonfluid milk products.

A general procedure followed for the assay of milk for ALP activity is shown as a flowchart in Figure 1. For all of the above-mentioned assays, it is necessary to run positive and negative controls and to closely follow the method procedures. Specific ALP method techniques are detailed below.

\section{Colorimetric Assays}

The earliest ALP assays were based on the use of reactions capable of generating chromogenic products. Most current colorimetric tests are based on the first phosphatase test (Kay and Graham, 1935). Colorimetric assays are still present as a means of testing (Rocco, 2004). In these tests, phenol is liberated from disodium phenyl phosphate substrate and reacted with a colorforming reagent. A slight improvement in sensitivity based on the use of added standards was achieved with the development of the Gilcreas (1941) method. However, these early assays have limited sensitivity and require 18 to $24 \mathrm{~h}$ to conduct. For improved accuracy and to reduce the assay time, several other tests have been developed. The specific advantages and disadvantages of those methods are detailed below.

Scharer Rapid Phosphatase Test. Scharer's rapid phosphatase test (Scharer, 1938) is based on the original Kay and Graham (1935) method, but offers a substantial reduction in analysis time $(\sim 75 \mathrm{~min})$. In short, ALP enzymatically cleaves a phosphate group from added disodium phenyl phosphate substrate. The released phenol group is extracted with butanol and then reacted with 2,6-dichloroquinone-chlorimide to form indophenol, a blue color compound (Figure 2). Under the controlled conditions of this assay, increased ALP activity in the milk sample results in the generation of an increasingly intense blue color. The intensity of the blue is compared visually against a set of standards or read instrumentally with a spectrophotometer. The results are expressed as micrograms of phenol per milliliter of milk.

The Scharer method (Scharer, 1943) has several weaknesses limiting its application and wide acceptance. First, the possibilities of phenol contamination from improperly cleaned glassware or from flavorants such as vanillin result in false positive assessments. To address this issue, Murthy et al. (1992) published several specific methods for glassware and utensil selection and cleaning. Second, the necessary reagents, as well as the formed indophenol chromagen, are unstable over time, resulting in an increased rate of false negatives (Scharer, 1943). Although rapid, inexpensive, and convenient, Scharer's rapid phosphatase test relies on subjective visual assessments of color development and is especially unreliable near the limit of detection or with colored product. A more objective method, based on spectrophotometric readings, has been proposed to confirm positive samples (Murthy et al., 1992) and has been reported to be capable of detecting approximately 0.1 to $0.2 \%$ contamination by raw milk in pasteurized milk (Angelino et al., 1999). Given the high pathogenicity and virulence of certain milk-borne human pathogens, this relatively high limit of detection may be considered inadequate from a food safety perspective. In fact, the 2009 US FDA PMO specifically ex- 


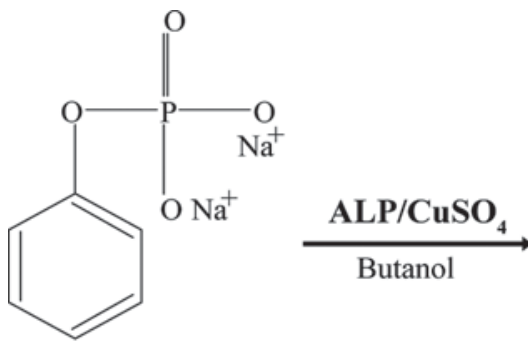

Disodium phenyl phosphate<smiles>O=P(O)(O)O</smiles>

Phenol

Phosphate

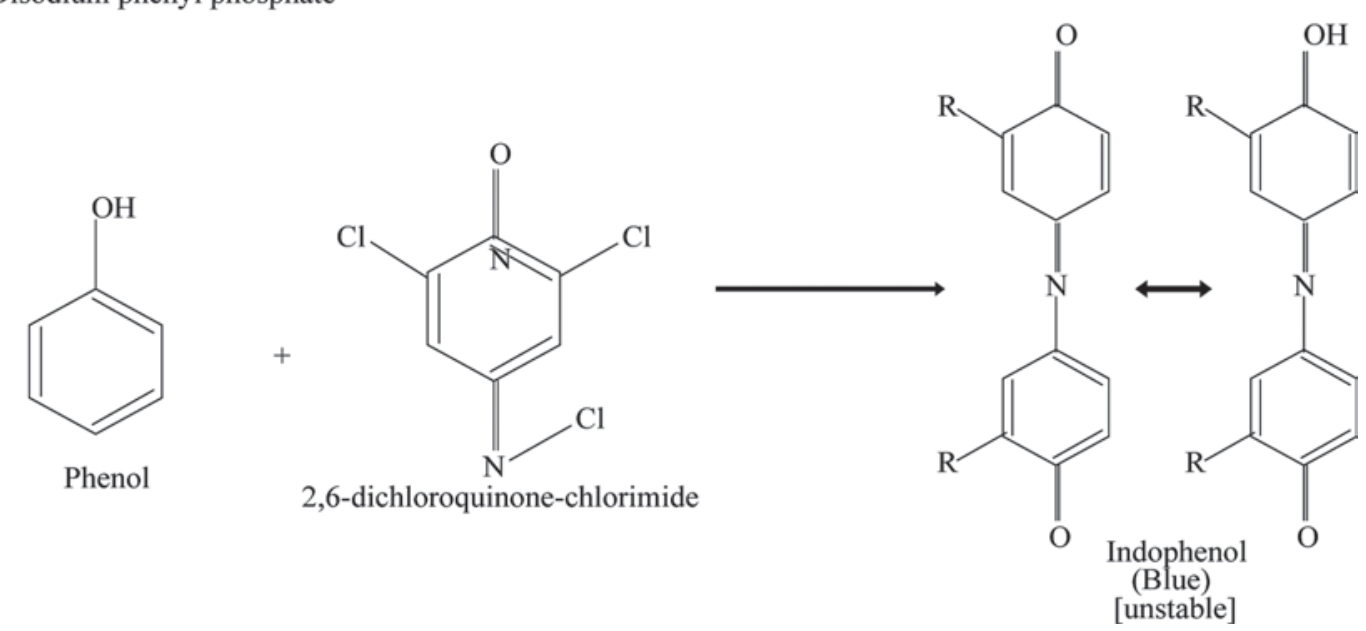

Figure 2. Chemical reactions detailing the basis of the colorimetric Scharer rapid alkaline phosphatase (ALP) test (Scharer, 1943).

cludes the use of ALP assays with a limit of detection of greater than $350 \mathrm{mU} / \mathrm{L}$, such as the Scharer rapid test. A few modifications for improved precision have been developed, as detailed below.

Rutgers Phosphatase Test. The use of butanol to extract the liberated phenol before the generation of color when using Scharer's test often results in the formation of an emulsion and reduces the efficiency of the extraction. To alleviate this source of error, Babson and Greeley (1967) used phenolphthalein monophosphate as the substrate. As ALP releases phenolphthalein, the concentration is then determined by titration with sodium hydroxide (Figure 3). Unlike the Scharer reagents, the phenolphthalein monophosphate substrate and its hydrolysis product are very stable over time and storage conditions typical for this assay.

Aschaffenburg and Mullen Test. In this test, $\rho$-nitrophenyl phosphate is used as the substrate of the reaction and the development of a yellow color is used as an indicator of the liberated nitrophenol (Figure 4; Aschaffenburg and Mullen, 1949). This method is characterized as being slightly more sensitive than the Kay and Graham method. Also, it does not require an extraction step or long incubation periods. This method is accepted under regulatory standards in the UK (Rocco, 2004).

\section{Fluorometric and Chemiluminescent Assays}

The analytical methods based on the fluorescence properties of certain compounds are extensively used in the chemical and biological sciences, especially for enzymatic assays where improved sensitivity is needed. Fernley and Walker (1965) published one of the first fluorometric assays for bovine ALP. The fluorometric assays are based on the ALP-mediated release of a phosphate radical from a self-indicating substrate, such as 4-methylumbelliferyl phosphate, to form a highly fluorescent product, 7-hydroxy-4-methyl-coumarin (4-methylumbelliferone), which has optimal fluorescence at $\mathrm{pH} 14$ (Yoshitomi, 2004). A monophosphorylated benzothiazole derivative as the self-indicating substrate also may be used for this reaction. Currently, a fluorogenic aromatic orthophosphoric monoester (Fluorophos, Advanced Instruments Inc., Needham Heights, MA) is used for ALP assay in milk and milk products. In this assay, a fluorescent compound, "Fluoroyellow," is produced by hydrolysis of the Fluorophos substrate and then analyzed using a fluorometer. The instrumental measurement of fluorescence generated over time is correlated to enzymatic activity or the concentration of ALP. This specific fluorometric assay is reported to be much more rapid (reported at $\sim 3 \mathrm{~min}$ ), simple, and 


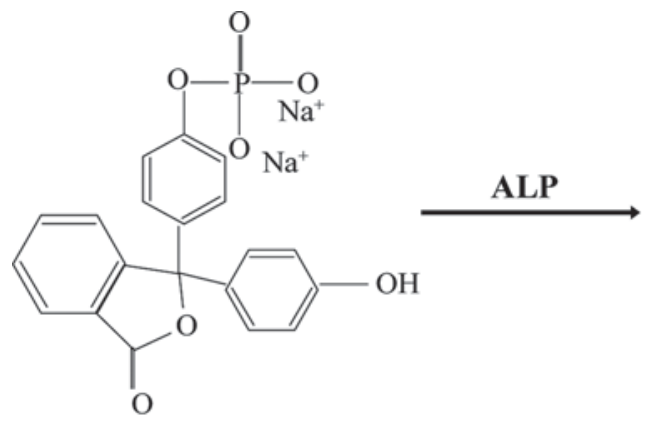

phenolphthalein monophosphate

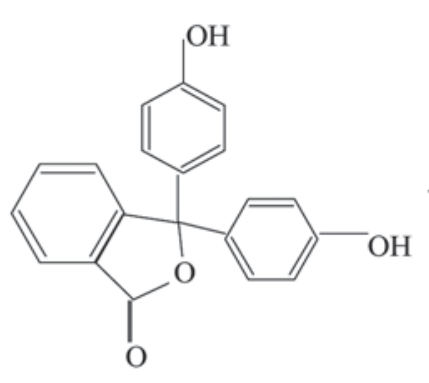

phenolphthalein<smiles>O=P(O)(O)O</smiles>

[Pink color]

Phosphate

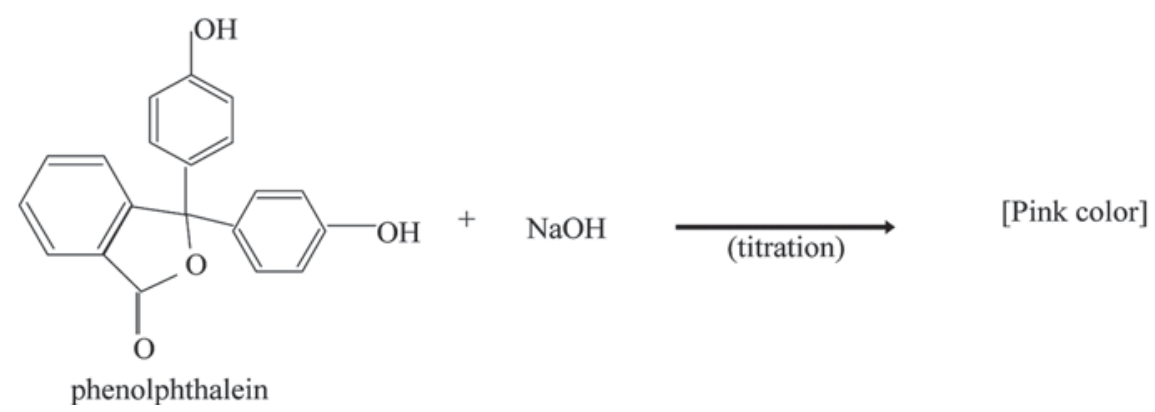

Figure 3. Chemical reactions detailing the basis of the colorimetric Rutgers alkaline phosphatase (ALP) test (Babson and Greeley, 1967).

about 100 to 1,000 times more sensitive than colorimetric assays such as the Scharer method (Fox and Kelly, 2006). As a result, this fluorometric assay is sufficiently sensitive to detect even small irregularities during milk processing (Rocco, 2004). An alternative fluorometric assay has been reported by Fenoll et al. (2002) for measuring residual ALP activity in a wide variety of solid and liquid dairy products. The method is based on the ALP-mediated hydrolysis of a nonfluorescent substrate, trifluoromethyl- $\beta$-umbelliferone phosphate, to its highly fluorescent phenolate product. The assay is performed in a reverse micellar medium composed of mixed buffer (2-amino-2-methyl-1-propanol buffer, $\mathrm{pH}$ 9.0, and borate buffer, $\mathrm{pH}$ 9.0) in dioctyl sodium sulfosuccinate/isooctane, at a temperature of $38^{\circ} \mathrm{C}$. The total test time is $450 \mathrm{~s}$ and the detection limits are 0.04, 0.4, and $0.22 \%$ (vol/vol) for raw milk, whole milk, chocolate milk, and butter, respectively (Fenoll et al., 2002).

The sensitivity, linearity, and repeatability of the Fluorophos system have been compared with the

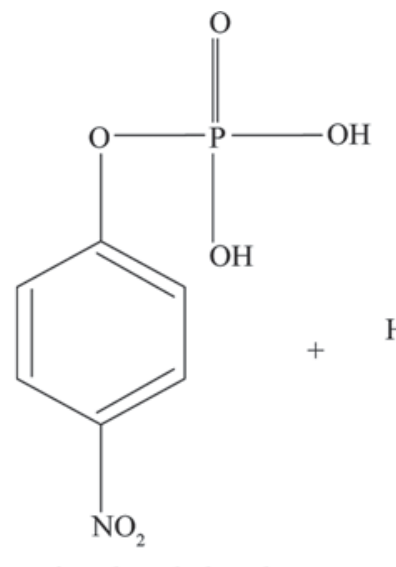

p-nitrophenyl phosphate

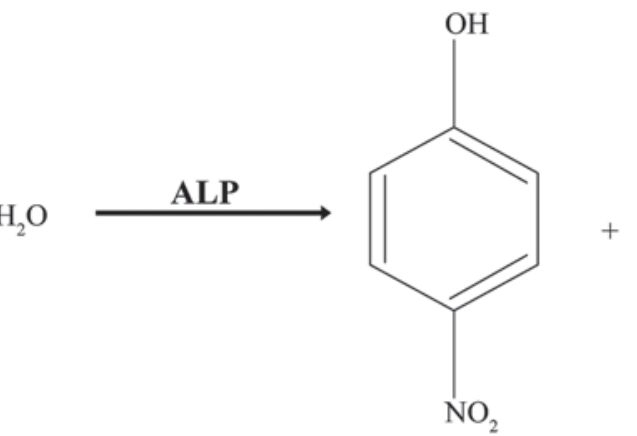

Nitrophenol (yellow color)

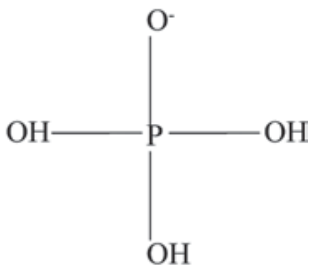

Phosphate

Figure 4. Chemical reactions detailing the basis of the colorimetric Aschaffenburg and Mullen (1949) alkaline phosphatase (ALP) test. 
Aschaffenburg and Mullen and Scharer colorimetric procedures for ALP testing in milk with raw milk additions, purified bovine ALP additions, and different heat treatments. The Fluorophos method has been reported to have high precision and repeatability and is both faster and simpler to perform than the traditional colorimetric tests (Payne and Wilbey, 2009). Many international trade and regulatory agencies accept fluorometric assays as a reliable test of pasteurization effectiveness for numerous dairy products. Current reports have established that the level of sensitivity of fluorometric assays is in the range of 0.003 to $0.006 \%$ raw milk contamination or about 25 to $50 \mathrm{mU} / \mathrm{L}$ of ALP (Black et al., 1993), a substantial improvement over colorimetric methods, where sensitivity ranges from 0.1 to $0.5 \%$ (Claeys et al., 2002). A fluorometric method is approved by FDA, NCIMS, AOAC International, the International Association for Standardization, and the International Dairy Federation, and is listed in the PMO.

Chemiluminescence is the basis for yet another approach to measuring ALP activity. Chemiluminescent assays for ALP analysis are based on the ALP-mediated dephosphorylation of adamantyl 1,2-dioxetan substrates (e.g., adamantyl-1,2-dioxetane phenylphosphate). This class of substrates is specifically recognized and cleaved by ALP to yield a phenoxide intermediate, which decomposes with the emission of a prolonged glow of light that can be read with a luminometer or refrigerated photon-counting device. This methodology provides a simple, one-reagent assay with a limit of detection of $1 \mathrm{zmol}$ (603 molecules) of enzyme (Kricka, 2003). A chemiluminescent assay with sensitivities and assay times similar to the fluorescent methods was developed to determine the concentration of ALP in milk by Girotti et al. (1994). The results agreed with those obtained by qualitative and quantitative absorption spectrometry for ALP, and the chemiluminescent method gave quantitative results without laborious solution and sample preparation. A chemiluminescent assay (Paslite, Charm Sciences Inc., Lawrence, MA) was reviewed and approved by FDA/NCIMS and the International Association for Standardization/International Dairy Federation (ISO 22160/IDF 209) and is, along with the fluorometric test, 1 of the 2 technologies specifically noted in the 2009 PMO as acceptable for ALP testing in grade A milk products.

An additional rapid chemiluminescent method also has gained validation from NCIMS in 2009 as an approved ALP assay. Referred to as the Fast Alkaline Phosphatase test (Charm Sciences Inc., Lawrence, MA), it is reported to have a limit of detection of 20 $\mathrm{mU} / \mathrm{L}$ of ALP activity in HTST milk. This rapid assay requires minimal sample size and preparation and is reported to have a response time of $45 \mathrm{~s}$.

\section{Limitation of ALP Assays}

The ALP assay is affected by many factors, such as the composition of the product being tested, the ability of ALP to regain activity, and the presence of microbial ALP. The following topics are presented to detail the possible areas of concern when conducting or applying the results of the ALP assay.

Compositional Factors. Several studies have shown that milk or milk product composition can affect ALP assays. Painter and Bradley (1997) performed ALP assays on milk and cream treated with various time and temperature conditions to determine ALP stability using a fluorometric method. This study demonstrated that increasing fat levels resulted in an increased residual ALP activity. The ALP in milk is reported to be associated with the MFGM and concentrated in the cream phase (Kosikowski, 1988). Products with elevated milkfat levels can have higher initial ALP values. Residual ALP values in nonfat milk are reported to be approximately $50 \%$ lower than in whole milk when pasteurized at minimal HTST time and temperature requirements (Painter and Bradley, 1997). Claeys et al. (2002) reported that although whole milk exhibits higher initial ALP activities than nonfat milk, the fat content might not be the sole factor that influences the result of pasteurized milk ALP test.

Interfering Compounds and Conditions. Colored dairy products, such as strawberry milk, pose an obvious interference challenge with colorimetric ALP assays. Other nonpigmented food additives with reactive phenolic groups, such as vanillin (when oxidized to vanillic acid), $\rho$-hydroxybenzoic acid, and salicylic acid, can interfere with the ALP assay substrate yielding false positive results (Murthy et al., 1992). Antibiotic residues of oxytetracycline and penicillin with phenolic moieties have been shown to give false positive results with colorimetric tests (Manolkidis et al., 1971). Similar observations have been found with pesticides containing polychlorinated biphenyls, due to the reactivity of phenyl groups (Kumar et al., 1973). Alkaline phosphatase activity has been shown to be inhibited by flavonoids, saccharides (Kuzuya et al., 1982), and ascorbic acid (Miggiano et al., 1983). Some polyphenolic compounds present in cocoa also are thought to have an inhibitory effect on ALP (Murthy et al., 1992). Sodium chloride $(0.25 \mathrm{M})$ is shown to reduce the thermal stability of ALP by approximately 50\% (Linden, 1979). Conversely, increased lactose concentration increases the thermal stability of ALP (Sanders et al., 1954). 
The ALP enzyme can undergo an irreversible loss of activity at acidic $\mathrm{pH}$ values typical of cultured milk and yogurt (Murthy et al., 1992). Recently in another study (Ma et al., 2001), carbon dioxide incorporated in dairy products for shelf life purposes had no significant effect on ALP activity. The use of proper controls for interfering substances, along with negative and positive control for such fortified products, is generally advised.

Methodology. As with most standard protocols, certain conditions may limit the accuracy and precision of all ALP assays. Each method should be administered with utmost attention to standard protocol. A negative control (a sample heated to $95^{\circ} \mathrm{C}$ for 1 min followed by rapid cooling) can be included to determine the effect of contamination from glassware, reagents, coloring materials, fat, and so on. A positive control ensures the performance of reagents and that the test is working properly (Murthy et al., 1979; Murthy, 1982). A portion of the negative control is mixed with 0.001 to $0.2 \%$ (based on sensitivity) of mixed herd fresh raw milk. In certain cases, a dose-response curve is obtained to test the lower detection limit of raw milk contamination. However, expressing the sensitivity of the method in this fashion is questionable as the ALP activity of raw milk varies greatly (from 119 to $4,380 \mu \mathrm{g}$ of phenol/0.5 $\mathrm{mL}$ of milk) depending on factors that include the stage of lactation and animal health (Haab and Smith, 1956).

Microbial Alkaline Phosphatase. Alkaline phosphatase is produced by many bacterial strains and, in many cases, exhibits a higher thermal stability than bovine ALP, potentially increasing the incidence of false positive results. Some of the reports to date suggest that certain bacterial cells produce heat-labile ALP, making it difficult to differentiate from residual bovine ALP (Knight and Fryer, 1989). Routine assays discussed above cannot directly distinguish between microbial or bovine ALP activity. As a result, the American Public Health Association recommends the repasteurization of any positive sample. If the ALP activity of the repasteurized sample is not noticeably reduced, it can be concluded that the original ALP assay result was due to the presence of heat-stable microbial ALP. Murthy and Kaylor (1990) suggested that because microbes can produce both heat-labile and heat-stable ALP, differentiating bovine and microbial ALP becomes especially problematic. Murthy and Kaylor (1990) recommend using agarose-gel electrophoresis to differentiate between microbial and bovine ALP. Psychrotrophic counts in raw milk before pasteurization of more than $1.2 \times 10^{7}$ $\mathrm{cfu} / \mathrm{mL}$ can have sufficient microbial ALP to cause a positive ALP test (Knight and Fryer, 1989). However, the current practices used to discriminate between such activities are based on the characteristic individual in- activation temperature of the reactivated and microbial ALP (Figure 1). Rosenthal et al. (1996) reported that cheeses inoculated with the mold Penicillium roqueforti manifest entirely heat-labile ALP activity.

Nonbovine Milk Products. Whereas most studies on ALP detection have been conducted on cow milk, few have focused on nonbovine milk and milk products (Harding and Garry, 2005; Moatsou, 2010). Although nonbovine dairy foods remain a relatively small market, the need remains to validate nonbovine dairy food pasteurization and understand the associated ALP activity. Many regulatory and industry entities recognize the utility of ALP assays for nonbovine milk based on the performance history of such assays, rather than a substantial research foundation. Limited literature is available to provide such foundational data for the application of ALP assays in milk products of nonbovine origin. Growing markets for such specialty dairy foods containing goat, sheep, or buffalo milk may increase the research attention to this area. Particular areas in need of scrutiny include denaturation kinetics and potential reactivation rates in nonbovine milk. A brief treatment of known literature is included below.

In general, goat milk has lower ALP activities when compared with cow milk (Mathur, 1974; Williams, 1986). The ALP activity in sheep milk has been reported to be 2 or 3 times higher than that of cow milk and increases throughout lactation (Scintu et al., 2000), from around 8,000 to $17,000 \mu \mathrm{g}$ of $\mathrm{phenol} / \mathrm{mL}$ (Klotz et al., 2008). Raynal-Ljutovaca et al. (2007) reported considerable variations in ALP contents between species, breed within species, and individual animals. The ranges of ALP concentrations in goat, sheep, and cow milk found by the authors were 115 to 1,$300 ; 8,300$ to 17,300 ; and 1,800 to $4,750 \mu \mathrm{g}$ of $\mathrm{phenol} / \mathrm{mL}$, respectively, and were apparently unrelated to the fat content of the milk samples. During the heat treatment of milks, more of the ALP activity in goat and sheep milks decreased compared with the ALP activity in cow milk (Vamvakaki et al., 2006). Some reports also suggest that ALP in sheep milk is slightly more sensitive to thermal denaturation than that in cow milk (Anifantakis and Rosakis, 1983). As such, some colorimetric methods have a substantially reduced sensitivity and have been shown to have a substantial failure rate at even $0.8 \%$ added raw milk levels. Williams and Nottingham (1990) modified the Aschaffenburg and Mullen assay procedure by increasing the sample volume and thus increasing the sensitivity for application to goat's milk. The ALP values in goat milk have been reported to vary widely with little or no correlation to milk fat, milk solids nonfat, and yield with a minimal seasonal effect (Williams and Nottingham, 1990). Barbosa (2005) suggested that the differences in the fat content of goat 
and sheep milks used for direct human consumption or cheese making have an effect on the performance of the ALP tests available. Klotz et al. (2008) determined and compared assays including colorimetric and fluorometric assays for ALP activity in goat and sheep milks to investigate the adequacy of current ALP standards. Klotz et al. (2008) concluded that fluorometric assay was more sensitive and repeatable compared with the colorimetric assay for ALP activity in goat and sheep milks.

Although only limited work has been done on many nonbovine milk sources, fewer studies have been conducted on buffalo milk than on goat and sheep milks. One study of buffalo milk demonstrated that ALP activity is generally slightly less relative to bovine milk and reactivation rates are similar to cow milk (Sharma and Ganguli, 1974). Lombardi et al. (2000) evaluated the activities and rates of inactivation of ALP in raw buffalo milk and found that at $60^{\circ} \mathrm{C}$, ALP showed the highest sensitivity to heat inactivation, and at $70^{\circ} \mathrm{C}$, ALP was completely inactivated. More recently, Sharma et al. (2009) reported that the activity of the ALP enzyme in goat milk was significantly lower than in bovine or buffalo milks. They found no significant difference in ALP activities in milks from bovines and buffalo and observed that ALP activities were concentrated in cream phase. The authors also reported that the thermal inactivation pattern of individual enzymes from bovine, buffalo, and goat milks was similar.

A study was conducted by the International Dairy Federation and the International Organization for Standardization to evaluate the reproducibility of a chemiluminescent method for ALP at 50, 100, 350, and $500 \mathrm{mU} / \mathrm{mL}$ in the whole milk of multiple species to meet new regulations in the US and proposed regulations in the EC. Fifteen laboratories from 8 countries evaluated bovine, goat, sheep, and buffalo milks; bovine skim milk; $20 \%$ fat cream; and $2 \%$ fat chocolate milk. The results of this study revealed that the method was comparable to the fluorometric assays in performance and indicating that the chemiluminescent method is suitable for measuring ALP in the milk of multiple species and in fluid dairy products at the US and EU levels of $<350 \mathrm{mU} / \mathrm{mL}$ (Salter and Fitchen, 2006).

In addition, Wernery et al. (2008) found that ALP cannot be used to evaluate the correct pasteurization of camel's milk as considerably greater temperatures are required to destroy ALP in camel's milk compared with ALP in cow's milk. The authors suggest the use of other enzymes such as lactoperoxidase (POD) or $\gamma$-glutamyltransferase as more suitable markers for the pasteurization of camel's milk. Similarly, it was observed that ALP is not a suitable indicative marker for confirmation of dromedary milk pasteurization as it is not in- activated at $72^{\circ} \mathrm{C}$, the accepted temperature for HTST pasteurization of other milks. $\gamma$-Glutamyltransferase has also been proposed by Wernery et al. (2006) as a possible candidate for the evaluation of dromedary milk pasteurization.

Nonfluid Dairy Products. Several other dairy products, such as butter and cheese, can be evaluated for pasteurization status using an ALP assay. The literature cites many modified methods to suit certain specific products such as colored milks (Kwee, 1985), flavored milks (International Dairy Federation, 1999), and other products, some of which are detailed below.

Due to the established microflora, processing parameters, and matrix effects, the ALP activity assessment in cheese is more complicated. Because many microbes can produce ALP, ripened and aged cheeses with increased microflora can yield a positive ALP test. Alkaline phosphatase is also reported to have a potential role in cheese ripening (Shakeel-Ur-Rehman et al., 2006). Time, temperature, and $\mathrm{pH}$ during cheese making are found to influence the denaturation of ALP (Battistotti et al., 1997). The ALP assays are considered able to detect cheese made from unpasteurized milk regardless of cheese age, provided that proper controls are in place. A control test was devised that consisted of cheese sample repasteurization at 62.8 or $66^{\circ} \mathrm{C}$ for 30 min (American Public Health Association method) to distinguish microbial and reactivated ALP. Pratt-Lowe et al. (1988) argued that because certain Mexican-style cheeses may have both heat-labile and -stable microbial ALP, the current ALP assay methods may be questionable for such products. A subsequent study (Murthy and Cox, 1988) also argued that heat lability of microbial ALP could be due to the presence of salt, which may have a role in increasing the ALP stability in cheese. Additional studies with Mexican-style (Pratt-Lowe et al., 1988) and blue-veined cheeses (Rosenthal et al., 1996) further questioned the ability of current methods to discriminate microbial and bovine ALP in cheese. Rosenthal et al. (1996) also reported that a raw-milk Grana-type cheese showed negative ALP assay results; such a result was attributed to the handling of curds at hot temperatures $\left(55^{\circ} \mathrm{C}, 1 \mathrm{~h}\right)$ in mildly acidic whey. The curd-handling effect on ALP also is noted in the ISO standard 11816-2:2003. The polarographic method for ALP published by Lechner and Wolfseder (1995) also is considered for use in cheese produced with raw milk, but the activity should be at least $500 \mathrm{mU} / \mathrm{g}$.

Most butter in the US is manufactured from fresh, pasteurized cream. A negative ALP activity test will result in such creams immediately after heating and cooling and when stored at temperatures below $4^{\circ} \mathrm{C}$. However, butter is known to yield false positives due to reactivation when the pasteurized cream/butter is 
stored at higher than $4.4^{\circ} \mathrm{C}$ for more than $24 \mathrm{~h}$ (Freeman et al., 1968). Differentiating residual ALP from reactivated ALP is difficult for several reasons. Karmas and Kleyn (1990) conducted a study on experimental and commercial butters to evaluate the different ALP activities (residual, microbial, and reactivated) using both the Official AOAC and Rutgers methods. Karmas and Kleyn (1990) found that unsalted butter always exhibited ALP activity, whereas the unsalted samples revealed very little or no activity. The AOAC method used by the authors, however, is unable to give information to distinguish between native, residual, and reactivated ALP activity. In a later study, the same authors stated that the AOAC method used to determine ALP was difficult to perform on butter due to the inappropriate incorporation of an aqueous $\mathrm{Mg}$ solution into a solid water-in-oil emulsion. Prewarming the butter to increase solubility may assist in the incorporation of $\mathrm{Mg}$, yet is not recommended when testing for reactivated ALP. It was concluded that the AOAC method was acceptable to determine ALP activity in butter, but it was unable to distinguish between native residual and reactivated ALP activity (Karmas and Kleyn, 1990). McKellar et al. (1988) examined and modified the AOAC methodology and developed techniques for sampling butter for ALP determination. Their results showed that melting butter at $40^{\circ} \mathrm{C}$ led to positive ALP reactions. The use of a cork borer to take a solid sample for analysis was an effective way to eliminate the reactivation of the enzyme during the analysis. Also, the addition of as little as $0.1 \mathrm{~m} M$ EDTA to freshly pasteurized cream was reported to aid in minimizing the reactivation of ALP resulting from temperature abuse of the samples. The use of a high-pH buffer (9.6) also helped in reducing the reactivation of the enzyme (McKellar et al., 1989).

Little contemporary literature has been published regarding ALP activity in ice cream and ice cream mix. In general, approaches to assaying ice cream for ALP include melting the product and allowing it to stand for 60 min to release air and inclusions such as nuts or candies. Despite the higher solid content, Hahn and Tracy (1939) showed that added serum solids did not affect ALP inactivation. Conversely, Caulfield and Martin (1939) demonstrated that added sucrose had a protective effect against thermal ALP inactivation. However, given the higher minimum pasteurization times and temperatures for ice cream mix, this effect was considered inconsequential.

Presence of Isozymes. Isozymes or isoenzymes are variants of enzymes that catalyze the same reaction, but have differences in AA sequence and can be distinguished by techniques such as electrophoresis or isoelectric focusing. Peereboom (1966) identified 3 different forms or isozymes of ALP from raw bovine cream and milk, designating them $\alpha-, \beta-$, and $\gamma$-ALP. Molecular weights of all 3 forms varied largely. During reactivation in pasteurized cream, only the $\beta$-isozyme was detected (Peereboom, 1968), suggesting that the $\beta$-isozyme form is primarily involved with the reactivation process. In a later theory on renaturation of ALP from pasteurized cream, Peereboom (1969) suggested that a part of the lipoprotein complex comprises the outer layer of the MFGM and includes the $\beta$-isozyme ALP. During heat treatment, the $\beta$-isozyme migrates into the water phase as denaturation proceeds. Upon cooling, as the denaturated $\beta$-isozyme is reincorporated into the MFGM environment, it recovers enzymatic activity. There is, accordingly, a marked increase in $\beta$-isozyme content in the MFGM.

Reactivation of Alkaline Phosphatase. Because the result of the ALP assay is considered indicative of the effectiveness of the milk pasteurization, the possibility of getting positive tests due to ALP reactivation also can be a problem when testing the activity of this enzyme in dairy products. Wright and Tramer (1953) were the first to recognize ALP reactivation. They reported that pasteurized milk could test positive for ALP activity when stored at temperatures ranging from 22 to $37^{\circ} \mathrm{C}$, even when a negative ALP result was obtained for the same pasteurized milk following processing. Cream heated to as low as $74^{\circ} \mathrm{C}$ with subsequent storage at $>30^{\circ} \mathrm{C}$ temperatures has also shown ALP reactivation (Lyster and Aschaffenburg, 1962). Murthy et al. (1976) conducted a series of experiments to demonstrate that the maximal reactivation of ALP in milk products occurred when heated to $104.4^{\circ} \mathrm{C}$, incubated at $34^{\circ} \mathrm{C}$, and adjusted to $\mathrm{pH}$ 6.5. They also found that raw milk subjected to rapid heating above $85^{\circ} \mathrm{C}$ is more susceptible to "reactivation or renaturation" of the ALP enzyme (Wright and Tramer, 1953). Subsequent research could not establish a correlation between reactivation, time/temperature of pasteurization, or postprocess storage time. It also was found that the propensity for reactivation varied in milk with no specific relationship to fat content, ascorbic acid, or metal ion content (Wright and Tramer, 1953a). It has been concluded that milk pasteurized at temperatures higher than $71.7^{\circ} \mathrm{C}$ is more prone to reactivation. In another study, cream heated to as low as $74^{\circ} \mathrm{C}$ with subsequent storage at $>30^{\circ} \mathrm{C}$ temperatures showed reactivation (Lyster and Aschaffenburg, 1962).

The role of metallic ions (e.g., magnesium acetate) in the reactivation of ALP has been the focus of several studies (Richardson et al., 1964; Kuzuya et al., 1982). The reported results suggest that $\mathrm{Mg}^{2+}$ along with $\mathrm{Zn}^{2+}$ are stimulatory to ALP activity reactivation, whereas $\mathrm{Co}^{2+}, \mathrm{Cu}^{2+}, \mathrm{EDTA}$, and $\mathrm{Sn}^{2+}$ may inhibit ALP reactiva- 
tion and reactivation depending on several factors such as the availability of free $\mathrm{Ca}^{2+}$ and $\mathrm{Mg}^{2+}$ ions, heating and storage conditions, availability of phosphates, and pH conditions (Sharma and Ganguli, 1974; Linden et al., 1977; Linden, 1979; Murthy and Peeler, 1979; Fox and Kelly, 2006). It has been reported that the reactivation process is imminent in UHT-treated milk when stored at ambient temperature. Homogenization before heat treatment has been found to reduce the reactivation rate. In later work, Painter and Bradley (1997) found that milks with low fat content are slightly less susceptible to reactivation. Another study (Gallusser and Bergner, 1981) showed the reactivation rate of ALP to have an inverse relationship with oxygen content; similarly, UHT milk with increased available oxygen showed less reactivation. It has been suggested that at high oxygen concentrations, the free sulfhydryl groups created during the heat treatment are later oxidized during storage, thus inhibiting sulfhydryl cross-linking reactions critical for the structure dependent activity of ALP.

Analytical steps to differentiate between residual and reactivated ALP are based on the premise that ALP will reactivate (4- to 10-fold increase in activity) in the presence of magnesium salts (Richardson et al., 1964). In such a situation, a finished pasteurized product may yield a false positive ALP assay. Whenever a false-positive test result is suspected due to reactivated ALP, the analyst should proceed according to the following assessments: (1) the milk in question is divided into 2 samples, treating 1 with a magnesium acetate solution to promote reactivation; (2) both samples are incubated at $34^{\circ} \mathrm{C}$ for $60 \mathrm{~min}$; (3) the sample is diluted by 6 -fold; and then (4) the sample is assayed for ALP activity. If the Mg-treated sample readings are equal to or higher than the control sample, the original ALP assay is considered as a result of reactivated ALP. Conversely, if the Mg-treated sample exhibits less activity than the control, the values are considered to be resulting from residual ALP. Deciphering the difference between residual and reactivated ALP activity can pose a problem for plant and regulatory personnel. This problem may be further complicated by the presence of microbial ALP.

\section{Alternative Methods}

The limitations of currently adopted technologies and the diversity of dairy products has led to the development of alternative methods of residual ALP determination. Noted alternatives are listed below; however, adoption and application of these methods has yet to occur with most recognized regulatory bodies.
Biostrip Technologies. Biostrips have grown in popularity as a means to diagnosis various diseases as well as for testing different chemical and biochemical parameters. Sharma et al. (2003) developed a test using dry-reagent strips for detection of ALP activity in milk. The test is based on ALP reaction with $p$-nitrophenyl phosphate in the presence of water to liberate $\rho$-nitrophenol and inorganic phosphate. The $\rho$-nitrophenol substrate reacts with a specific chromogen that changes the color of the strip from light blue to green, which can be directly visualized. The strip method has a sensitivity of $>0.5 \mathrm{U} / \mathrm{L}$ and is stable at room temperature for several months. This method is proposed as an alternative for dairy industries and remote areas where expensive instruments are unavailable. Another system, the Reflectoquant strip rapid test, also has been used to measure the inactivation of enzymes including ALP, lipase, and POD in milk. Martin et al. (2005) reported using it to differentiate between shorttime-heated and high-temperature-heated milk through ALP and POD inactivation. This ALP assay requires a 20 -min incubation at $37^{\circ} \mathrm{C}$ and has a measuring range of 1.0 to $10 \mathrm{U} / \mathrm{L}$.

Electrochemical Assays. Alkaline phosphatase activity can be determined electrochemically using an amperometric graphite-Teflon composite tyrosinase biosensor (Serra et al., 2005). This electrochemical assay developed by Serra et al. (2005) is a rapid (5-min) and highly sensitive $\left(6.7 \times 10^{-14} M\right.$ detection limit for ALP) test for the measurement of ALP activity, and it does not require an incubation step. In this assay, ALP activity is determined using phenyl phosphate as substrate, which is enzymatically dephosphorylated to form phenol. The phenol generated by the action of ALP is oxidized to quinone by immobilized tyrosinase. At the tyrosinase composite electrode surface, quinone is reduced to catechol that is then reoxidized by tyrosinase to quinone producing a redox cycle that produces the amplification of electrochemical signal obtained at the biosensor and the sensitive detection of ALP (Serra et al., 2005; Fox and Kelly, 2006).

The use of 4-nitrophenylphosphate as the substrate for a potentiometric assessment of ALP in milk and dairy products has been described by Hassan et al. (2009). The sensor measures the decrease of a fixed concentration of 4-nitrophenylphosphate substrate as a function of the enzyme activity. This assay is reported to exhibit good selectivity and stability with a detection limit of $6.3 \times 10^{-6} M$ over the $\mathrm{pH}$ range of 4.5 to 10 . The results obtained were reported to agree fairly well with data obtained from spectrophotometric methods.

Immunochemical Assays. Enzyme-linked immunosorbent assays represent a commonly used technol- 
ogy for the quantification of organic molecules. The advantages of this method are increased sensitivity and specificity. Based on the antigenic nature of the ALP molecule, Vega-Warner et al. (2000) demonstrated the ability of competitive indirect (CI) ELISA to discriminate between microbial and milk ALP, a feature that the previous methods are not capable of directly achieving. However, the CI-ELISA methods (Vega-Warner et al., 2000) have been developed in relatively simple model systems and have yet to be validated in actual foods such as milk. The CI-ELISA uses antibodies specific for bovine milk ALP. An immunoglobulin specific for bovine milk (BM-ALP) was obtained and proved to be effective in differentiating between BM-ALP and $E$. coli ALP and quantifying BM-ALP in whole and skim milk in the presence of E. coli ALP (Chen et al., 2006). Monoclonal antibodies specific for the bovine milk ALP that do not react with the enzymes of intestinal or bacterial origin have also been prepared by Geneix et al. (2007). This method was reported as the first immunoassay suitable to detect raw milk in boiled milk down to a $0.02 \%$ dilution and, in contrast with CIELISA, this method does not require the use of purified ALP. This immunoassay was also used to study the kinetics of ALP heat denaturation in bovine milk over a range from 50 to $60^{\circ} \mathrm{C}$ for 5 to $60 \mathrm{~min}$, and the results of the immunoassay were highly correlated with those obtained by standard colorimetric assays (Levieux et al., 2007). Although not currently approved for use by regulatory agencies, the development of an immunological assay could potentially reduce the error rates resulting from the difficulties the current technologies have in differentiating between microbial, residual, and reactivated ALP, as detailed above. Aside from including experimental controls, as is done in any ALP assay, the ability of an immunochemical assay to differentiate between residual (native), thermally denatured (inactive), and reactivated (renatured) ALP would require that the ALP molecule manifest sufficiently different antigenic determinants or domains. Although ELISA has been shown to be capable of differentiating between native and denatured ALP, reports of successful differentiation between native and reactivated ALP are lacking. Such a development would require the denatured ALP molecule to renature into a different conformational state than the native molecule. Currently no approved immunochemical assay exists for the routine assessment of ALP activity in milk or milk products.

Polarographic Assay. A polarographic method for the determination of the ALP was published by Davídek et al. (1976) and was modified by Lechner and Wolfseder (1995) with a limit of detection of $400 \mathrm{mU} / \mathrm{L}$. The polarographic method is more time consuming, less exact, insufficiently sensitive relative to the other electronic technologies, and has not been accepted or approved by US or EC regulatory authorities.

\section{DISCUSSION}

Under standard conditions of assay, the ALP method has been shown to be a remarkably valuable tool for the routine assessment of milk pasteurization validation, yet some concerns still exist. Reactivation and microbial ALP still cause concern and regulatory difficulties especially for UHT-processed products that are stored at room temperatures. Research has recently led to the reduction of the maximum residual limit in grade A products to $350 \mathrm{mU} / \mathrm{L}$ (Painter and Bradley, 1997; International Dairy Federation, 1999). Painter and Bradley (1997) found less than $150 \mathrm{mU} / \mathrm{L}$ of ALP activity in underpasteurized low-fat milk. In a collaborative study with a fluorometric assay, Rocco (1990) found that milk contaminated with as much as $0.5 \%$ raw milk showed less than $265 \mathrm{mU} / \mathrm{L}$ of ALP activity, thereby stressing the need to reconsider current regulatory standards. An additional study (Klotz et al., 2008) on cow, goat, and sheep milks also suggests that the present limit of $350 \mathrm{mU} / \mathrm{L}$ can be reduced further given that raw goat milk ALP levels were $<350 \mathrm{mU} / \mathrm{L}$. The high sensitivity of the fluorometric and chemiluminescent methods has further motivated such consideration. The most accurate ALP assay results are those done on product immediately after heat treatment, before storage time and microbial growth may allow extraneous ALP activities to appear (i.e., 0 time analysis). Nonbovine milk ALP requires additional scrutiny. Much of the data reported on nonbovine milks has yet to be thoroughly explored. Many of the recent studies have been conducted using technologies that are decades old. Additionally, more fundamental details for the kinetics of ALP denaturation and reactivation rates have yet to be thoroughly described for nonbovine species.

\section{REFERENCES}

Angelino, P. D., G. L. Christen, M. P. Penfield, and S. Beattie. 1999. Residual alkaline phosphatase activity in pasteurized milk heated to various temperatures-measurement with the Fluorophos and Scharer rapid phosphatase tests. J. Food Prot. 62:81-85.

Anifantakis, E. M., and P. S. Rosakis. 1983. Alkaline phosphatase activity of sheep milk and some factors affecting it. Egyptian J. Dairy Sci. 11:173-182.

Aschaffenburg, R., and J. E. C. Mullen. 1949. A rapid and simple phosphatase test for milk. J. Dairy Res. 16:58-67.

Babson, A. L., and S. J. Greeley. 1967. New substrate for alkaline phosphatase in milk. J. Assoc. Off. Anal. Chem. 50:555-557.

Barbosa, M. 2005. Interest in controlling alkaline phosphatase activity in sheep and goat milks. Pages 117-127 in Proc. International Symposium, Zaragoza, Spain. Special issue. International Dairy Federation, Brussels, Belgium.

Battistotti, B., E. Brambilla, F. Cappa, and G. Ferrandi. 1997. Alkaline phosphatase in milk and ripened cheeses. Sci. Tecn. Latt. Cas. 48:157-162. 
Black, R. G., M. Kuzyk, and J. Duggan. 1993. Evaluation of a fluorometric assay for alkaline phosphatase in fluid dairy products. Aust. J. Dairy Technol. 47:164-167.

Bortolato, M., F. Besson, and M. Roux. 2002. An infrared study of the thermal and $\mathrm{pH}$ stabilities of the GPI-alkaline phosphatase from bovine intestine. Biochem. Biophys. Res. Commun. 292:874879 .

Burgwald, L. H. 1939. The phosphatase test. A review of the literature on its application for detecting irregularities in the pasteurization of milk and dairy products. J. Dairy Sci. 22:853-872.

Caulfield, W. J., and W. H. Martin. 1939. Certain factors affecting the phosphatase test when applied to ice cream. J. Dairy Sci. 22:261-270.

Chen, C. C., Y. C. Tai, S. C. Shen, Y. Y. Tu, M. C. Wu, and H. M. Chang. 2006. Detection of alkaline phosphatase by competitive indirect ELISA using immunoglobulin in yolk (IgY) specific against bovine milk alkaline phosphatase. Food Chem. 95:213-220.

Claeys, W. L., A. M. van Loey, and M. E. Hendrickz. 2002. Kinetics of alkaline phosphatase and lactoperoxidase inactivation, and of B-lactoglobulin denaturation in milk with different fat content. J. Dairy Res. 69:541-553.

Davídek, J., J. Egertová, and J. Seifert. 1974. Further utilisation of 2-naphthol esters: Polarographic determination of phosphatase and arylsulphatase activities. Z. Lebensm. Unters. F A. 156:263265.

DHHS-FDA. 2007. Grade "A" Pasteurized Milk Ordinance. US Department of Health and Human Services, US Food and Drug Administration, Washington, DC.

dos Anjos, F., A. Machado, C. Ferro, F. Otto, and E. Bogin. 1998. Gamma-glutamyltransferase as a marker for the pasteurization of milk. J. Food Prot. 61:1057-1059.

Eckner, K. F. 1992. Fluorometric analysis of alkaline phosphatase inactivation correlated to Salmonella and Listeria inactivation. J. Food Prot. 55:960-963.

Fenoll, J., G. Jourquin, and J. M. Kauffmann. 2002. Fluorimetric determination of alkaline phosphatase in solid and fluid dairy products. Talanta 56:1021-1026.

Fernley, H. N., and P. G. Walker. 1965. Kinetic behavior of calf-intestinal alkaline phosphatase with 4-methylumbelliferyl phosphate. Biochem. J. 97:95-103.

Fox, P. F., and A. L. Kelly. 2006. Indigenous enzymes in milk: Overview and historical aspects - Part 2. Int. Dairy J. 16:517-532

Freeman, T. R., J. L. Bucy, A. W. Rudnick Jr., and W. F. Lewallen. 1968. Survey of reactivation of butter. J. Dairy Sci. 51:18751876.

Gallusser, A., and K. G. Bergner. 1981. Reactivation of alkaline phosphatase in UHT milk, depending on its oxygen content. Deut. Lebensm. Rundsch. 77:441-444.

Geneix, N., E. Dufour, A. Venien, and D. Levieux. 2007. Development of a monoclonal antibody-based immunoassay for specific quantification of bovine milk alkaline phosphatase. J. Dairy Res. 74:290-295.

Gilcreas, F. W. 1941. Report on tests for pasteurization of dairy products. Phosphatase test in examination of milk and cream. III. Rapid [laboratory] test. J. Assoc. Off. Agric. Chem. 24:559-564.

Girotti, S., E. Ferri, S. Ghini, R. Budini, and A. Roda. 1994. Chemiluminescent assay of alkaline phosphatase in milk. Neth. Milk Dairy J. $48: 213-224$.

Haab, W., and L. M. Smith. 1956. Variations in alkaline phosphatase activity of milk. J. Dairy Sci. 39:1644-1650.

Hahn, A. J., and P. H. Tracy. 1939. Determining the efficiency of icecream mix pasteurization through the use of the phosphatase test. J. Dairy Sci. 22:219-227.

Harding, F. 1991. Alkaline phosphatase test as a measure of correct pasteurization. Bulletin 262. Int. Dairy Fed., Brussels, Belgium.

Harding, F., and E. Garry. 2005. Collaborative evaluation of a fluorometric method for measuring alkaline phosphatase activity in cow's, sheep's, and goat's milk. J. Food Prot. 68:1047-1053.

Hassan, S. S. M., H. E. M. Sayour, and A. H. Kamel. 2009. A simple-potentiometric method for determination of acid and alkaline phosphatase enzymes in biological fluids and dairy products using a nitrophenyl phosphate plastic membrane sensor. Anal. Chim. Acta 640:75-81.

International Dairy Federation. 1999. Milk and milk-based drinks. Determination of alkaline phosphatase activity using a fluorimetric method. IDF-Standard 155A:3. International Dairy Federation, Brussels, Belgium.

Karmas, R., and D. H. Kleyn. 1990. Determination and interpretation of alkaline phosphatase activity in experimental and commercial butters. J. Dairy Sci. 73:584-589.

Kay, H. D., and W. R. Graham, Jr.. 1935. The phosphatase test for pasteurized milk. J. Dairy Res. 6:191-203.

Klotz, V., A. Hill, K. Warriner, M. Griffiths, and J. Odumeru. 2008. Assessment of the colorimetric and fluorometric assays for alkaline phosphatase activity in cow's, goat's, and sheep's milk. J. Food Prot. 71:1884-1888.

Knight, A. H., and S. M. Fryer. 1989. The development of heat-resistant phosphatase activity in raw milk. J. Soc. Dairy Technol. 42:81-86.

Kosikowski, F. V. 1988. Enzyme behavior and utilization in dairy technology. J. Dairy Sci. 71:557-573.

Kricka, L. J. 2003. Clinical applications of chemiluminescence. Anal. Chim. Acta 500:279-286.

Kumar, P., R. K. Sud, and K. G. Gupta. 1973. Interference of some pesticides in the milk phosphatase pasteurization test. J. Dairy Sci. 56:553-557.

Kuzuya, Y., Y. Kanamaru, and T. Tanahashi. 1982. Purification of bovine milk alkaline phosphatase with affinity chromatography and effect of flavonoids and saccharides on the enzyme activities. Nippon Chikusan Gakkaiho 53:45-49.

Kwee, W. S. 1985. An improved Aschaffenburg and Mullen alkaline phosphatase test for coloured milk products. Aust. J. Dairy Technol. 40:27-30.

Lechner, E., and K. Wolfseder. 1995. Experiences with a polarographic method for the determination of the activity of alkaline phosphatase (ALP) in milk and cheese. Milchwissenschaft 50:687-689.

Levieux, D., N. Geneix, and A. Levieux. 2007. Inactivation-denaturation kinetics of bovine milk alkaline phosphatase during mild heating as determined by using a monoclonal antibody-based immunoassay. J. Dairy Res. 74:296-301.

Linden, G. 1979. Biochemical study of some aspects of milk alkaline phosphatase reactivation. Milchwissenschaft 34:329-332.

Linden, G., D. T. Chappelet-Tordo, and M. Lazdunski. 1977. Milk alkaline phosphatase stimulation by $\mathrm{Mg}^{2+}$ and properties of $\mathrm{Mg}^{2+}$ site. Biochim. Biophys. Acta 483:100-106.

Lombardi, P., L. Avallone, A. D'Angelo, T. Mor, and E. Bogin. 2000. Buffalo-milk enzyme levels, their sensitivity to heat inactivation, and their possible use as markers for pasteurization. J. Food Prot. 63:970-973.

Lyster, R. L. J., and R. Aschaffenburg. 1962. The reactivation of milk alkaline phosphatase after heat treatment. J. Dairy Res. 29:2135.

Ma, Y., D. M. Barbano, J. H. Hotchkiss, S. Murphy, and J. M. Lynch. 2001. Impact of $\mathrm{CO}_{2}$ addition to milk on selected analytical testing methods. J. Dairy Sci. 84:1959-1968.

Manolkidis, K. S., E. Alichanidis, and A. G. Varvoglis. 1971. Effects of some antibiotics on the milk phosphatase pasteurization test. J. Dairy Sci. 54:335-338.

Martin, D., C. Kiesner, P. C. Lorenzen, and E. Schlimme. 1998. Adenosine deaminase (EC 3.5.4.4.) A potential indicator of heat treatment for the distinction of short-time and high-temperature pasteurized milk from the market. Kieler Milchw. Forsch. 50:225233

Martin, D., W. Linxweiler, D. Tanzer, R. Vormbrock, R. Olt, C. Kiesner, and H. Meisel. 2005. Use of the Reflectoquant ${ }^{\circledR}$ rapid tests for determination of thermal inactivation of the indigenous milk enzymes lipase, alkaline phosphatase and lactoperoxidase. Deut. Lebensm. Rundsch. 101:281-286.

Mathur, M. P. 1974. Studies on alkaline phosphatase in goat milk. Indian J. Dairy Sci. 28:145-147. 
McKellar, R. C., H. Cholette, and D. B. Emmons. 1988. Modification of the alkaline-phosphatase assay for butter. Can. Inst. Food Sci. Technol. J. 21:97-101.

McKellar, R. C., H. Cholette, and D. B. Emmons. 1989. Alkalinephosphatase in butter. Dairy Ind. Int. 54:33-34.

McKellar, R. C., H. W. Modler, H. Couture, A. Hughes, P. Mayers, T Gleeson, and W. H. Ross. 1994. Predictive modeling of alkalinephosphatase inactivation in a high-temperature short-time pasteurizer. J. Food Prot. 57:424-430.

Miggiano, G. A., A. Mordente, G. E. Martorana, E. Meucci, and A. Castelli. 1983. In vitro effect of ascorbic acid on bovine kidney alkaline phosphatase activity. Acta Vitaminol. Enzymol. 5:153158.

Moatsou, G. 2010. Indigenous enzymatic activities in ovine and caprine milks. Int. J. Dairy Technol. 63:16-31.

Murthy, G. K. 1982. Preparation of a positive control sample for use in the routine analysis of milk and milk products for alkaline phosphatase. J. Food Prot. 45:108-111.

Murthy, G. K., and S. Cox. 1988. Evaluation of APHA and AOAC methods for phosphatase in cheese. J. Assoc. Off. Anal. Chem. 71:1195-1199.

Murthy, G. K., S. Cox, and L. Kalyor. 1976. Reactivation of alkaline phosphatase an ultra high-temperature, short-time processed liquid milk products. J. Dairy Sci. 59:1699-1710.

Murthy, G. K., and L. O. Kaylor. 1990. Evaluation of APHA and AOAC II methods for phosphatase in butter and differentiation of milk and microbial phosphatase by agarose-gel electrophoresis. J. Assoc. Off. Anal. Chem. 73:681-687.

Murthy, G. K., D. H. Kleyn, T. Richardson, and R. M. Rocco. 1992 Alkaline phosphatase methods. Pages 413-431 in Standard Methods for the Examination of Dairy Products. R. T. Marshall, ed. Am. Publ. Health. Assoc., Washington, DC.

Murthy, G. K., R. Martin, U. S. Rhea, and J. T. Peeler. 1979. Rapid colorimetric test for alkaline phosphatase in dairy food products. J. Food Prot. 42:794-799.

Murthy, G. K., and J. T. Peeler. 1979. Rapid methods for differentiating reactivated from residual phosphatase in milk and cream: Collaborative study. J. Assoc. Off. Anal. Chem. 62:822-827.

Painter, C. J., and R. L. Bradley, Jr.. 1997. Residual alkaline phosphatase activity in milks subjected to various time-temperature treatments. J. Food Prot. 60:525-530.

Payne, C., and R. A. Wilbey. 2009. Alkaline phosphatase activity in pasteurized milk: A quantitative comparison of Fluorophos and colourimetric procedures. Int. J. Dairy Technol. 62:308-314.

Peereboom, C. J. W. 1966. Studies on alkaline milk phosphatase I. Non-identity of raw and reactivated alkaline phosphatase from cream. Neth. Milk Dairy J. 20:113-122.

Peereboom, C. J. W. 1968. Studies on alkaline milk phosphatase II. Occurrence of various phosphatase isoenzymes in dairy products. Neth. Milk Dairy J. 22:138-152.

Peereboom, C. J. W. 1969. Theory on the renaturation of alkaline milk phosphatase from pasteurized cream. Milchwissenschaft 24:266-269.

Picart, L., M. Thiebaud, M. Rene, J. P. Guiraud, J. C. Cheftel, and E. Dumay. 2006. Effects of high pressure homogenisation of raw bovine milk on alkaline phosphatase and microbial inactivation. A comparison with continuous short-time thermal treatments. J. Dairy Res. 73:454-463.

Pratt-Lowe, E. L., R. M. Geiger, and T. R. M. Richardson. 1988 Heat resistance of alkaline phosphatase produced by microorganisms isolated from California Mexican-style cheese. J. Dairy Sci. $71: 17-23$.

Rademacher, B., and J. Hinrichs. 2006. Effects of high pressure treatment on indigenous enzymes in bovine milk: Reaction kinetics, inactivation and potential application. Int. Dairy J. 16:655-661.

Raynal-Ljutovaca, K., Y. W. Park, F. Gaucheron, and S. Bouhallab. 2007. Heat stability and enzymatic modifications of goat and sheep milk. Small Rumin. Res. 68:207-220.

Richardson, L. A., E. F. McFarren, and J. E. Campbell. 1964. Dynamic state of milk: Phosphatase reactivation. J. Dairy Sci $47: 205-210$.
Rocco, R. M. 1990. Fluorometric determination of alkaline phosphatase in fluid dairy products: Collaborative study. J. Assoc. Off. Anal. Chem. 73:842-849.

Rocco, R. M. 2004. Alkaline phosphatase methods. Chapter 14 in Standard Methods for the Examination of Dairy Products. 17th ed. H. M. Wehr and J. F. Frank, ed. American Public Health Association, Washington, DC.

Rosenthal, I., S. Bernstein, and B. Rosen. 1996. Alkaline phosphatase activity in Penicillium roqueforti and in blue-veined cheeses. J. Dairy Sci. 79:16-19.

Salter, R. S. and J. Fitchen. 2006. Evaluation of a chemiluminescence method for measuring alkaline phosphatase activity in whole milk of multiple species and bovine dairy drinks: Interlaboratory study. J. AOAC Int. 89:1061-1070.

Sanders, G. P., and O. S. Sager. 1948. Heat inactivation milk phosphatase in dairy products . J. Dairy Sci. 31:845-857.

Sanders, G. P., O. S. Sager, and J. A. Hupfer. 1954. Factors affecting the sensitivity and accuracy of the phosphatase test. J. Dairy Sci. $37: 698-710$.

Scharer, H. 1938. A rapid phosphomonoesterase test for control of dairy pasteurization. J. Dairy Sci. 21:21-34.

Scharer, H. 1943. Laboratory control of milk under war conditions. The rapid phosphatase test. Am. J. Public Health Nations Health 33:396-398.

Schlimme, E., C. Kiesner, P. C. Lorenzen, and D. Martin. 1997. Chemical process parameters for thermal inactivation of alkaline phosphatase in milk. Kieler Milchw. Forsch. 49:207-219.

Schlimme, E., C. Kiesner, P. C. Lorenzen, and D. Martin. 1998. Influence of heat treatment of milk on the activities of the indigenous milk enzymes alkaline phosphatase and adenosine deaminase. Bull. Int. Dairy Fed. 332:25-31.

Scintu, M. F., E. Daga, and A. Ledda. 2000. Evaluation of spectrophotometric and fluorometric methods for alkaline phosphatase activity determination in ewe's milk. J. Food Prot. 63:1258-1261.

Serra, B., M. D. Morales, A. J. Reviejo, E. H. Hall, and J. M. Pingarron. 2005. Rapid and highly sensitive electrochemical determination of alkaline phosphatase using a composite tyrosinase biosensor. Anal. Biochem. 336:289-294.

Shakeel-Ur-Rehman, N. Y Farkye, and B. Yim. 2006. A preliminary study on the role of alkaline phosphatase in cheese ripening. Int Dairy J. 16:697-700.

Shakeel-Ur-Rehman, C. M. Fleming, N. Y. Farkye, and P. F. Fox. 2003. Indigenous phosphatases in milk. Pages 523-544 in Advanced Dairy Chemistry. Vol. 1: Proteins. 3rd ed. P. F. Fox and P. L. H. McSweeney, ed. Kluwer Academic/Plenum Publishers, New York, NY

Shamsi, K., C. Versteeg, F. Sherkat, and J. Wan. 2008. Alkaline phosphatase and microbial inactivation by pulsed electric field in bovine milk. Innov. Food Sci. Emerg. Technol. 9:217-223.

Sharma, R., S. Kaur, Y. S. Rajput, and R. Kumar. 2009. Activity and thermal stability of indigenous enzymes in cow, buffalo and goat milk. Milchwissenschaft 64:173-175.

Sharma, R. S., and N. C. Ganguli. 1974. Purification and properties of reactivated alkaline phosphatase from buffalo milk. Milchwissenschaft. 29:79-84.

Sharma, S. K., N. Sehgal, and A. Kumar. 2003. Dry-reagent strips for testing milk pasteurization. Lebensm. Wiss. Technol. 36:567571.

Suzuki, U., K. Yoshimura, and M. Takaishi. 1907. Uber ein enzym "phytase" das anhydro-oxy-methylen-diphosphorsaure spaltet. Bull. Coll. Agric. Tokyo Imp. Univ. 7:503-512.

Vamvakaki, A. N., E. Zoidou, G. Moatsou, M. Bokari, and E. Anifatakis. 2006. Residual alkaline phosphatase activity after heat treatment of ovine and caprine milk. Small Rumin. Res. 65:237-241.

Van Bever, A. K. 1943. The influence of temperature and pasteurizing time upon the enzymes and bacteria in milk. Enzymologia 11:7-18.

Vega-Warner, A. V., H. Gandhi, D. M. Smith, and Z. Ustunol. 2000 Polyclonal-antibody-based ELISA to detect milk alkaline phosphatase. J. Agric. Food Chem. 48:2087-2091. 
Vega-Warner, A. V., C. H. Wang, D. M. Smith, and Z. Ustunol. 1999. Milk alkaline phosphatase purification and production of polyclonal antibodies. J. Food Sci. 64:601-605.

Wernery, U., S. Fischbach, B. Johnson, and S. Jose. 2008. Evaluation of alkaline phosphatase (ALP), $\gamma$-glutamyl transferase (GGT) and lactoperoxidase (LPO) activities for their suitability as markers of camel milk heat inactivation. Milchwissenschaft 63:265-267.

Wernery, U., U. Maier, B. Johnson, R. M. George, and F. Braun. 2006. Comparative study on different enzymes evaluating heat treatment of dromedary milk. Milchwissenschaft 61:281-285.

Williams, D. J. 1986. A modification to the Aschaffenburg and Mullen alkaline phosphatase test suitable for goat's milk. Aust. J. Dairy Technol. 41:28-30.
Williams, D. J., and S. M. Nottingham. 1990. Suitability of a modification to the Aschaffenburg and Mullen alkaline phosphatase test or goats' milk: Collaborative study. Aust. J. Dairy Technol. 45:21-23.

Wright, R. C., and J. Tramer. 1953. Reactivation of milk phosphatase following heat treatment I. J. Dairy Res. 20:177-188.

Wright, R. C., and J. Tramer. 1953a. Reactivation of milk phosphatase following heat treatment II. J. Dairy Res. 20:258-273.

Wright, R. C., and J. Tramer. 1956. Reactivation of milk phosphatase following heat treatment IV. The influence of certain metallic ions. J. Dairy Res. 23:248-256.

Yoshitomi, K. 2004. Alkaline phosphatase activity in cheeses measured by fluorometry. Int. J. Food Sci. Technol. 39:349-353. 